PNL-SA- -18313

DE91 004067

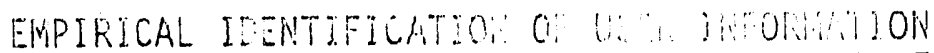

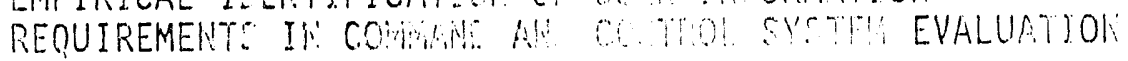

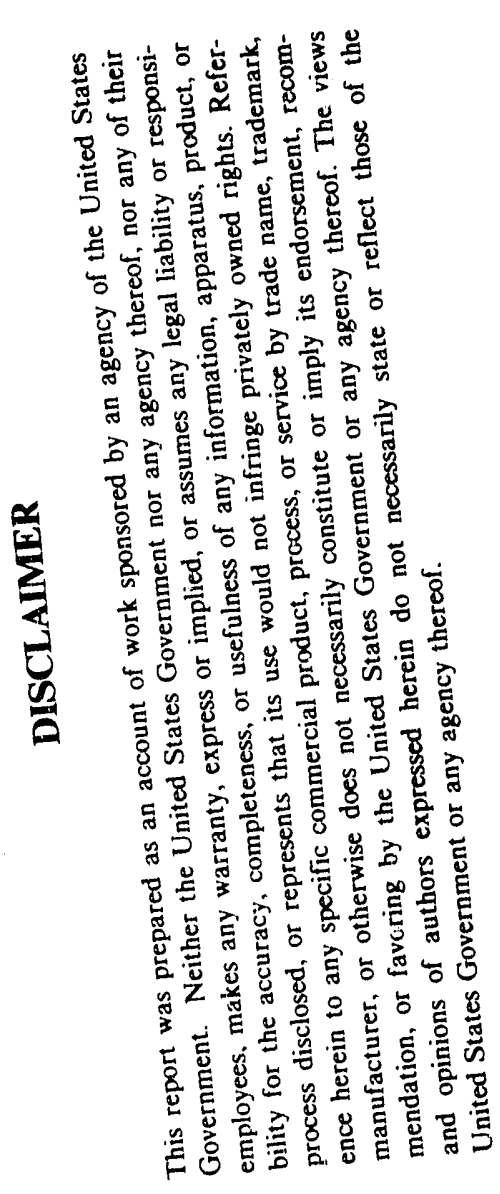

H. C. McCaijum (a;

A. C. Bittner, Jr.

R. V. Badalamente.

iune 1990

Presented at the

1990 Human Factor: 5.

Orlando, Florida

october 21-26, 199 !

liork supported by the Commanui

U.S. Army Tactical Command anc

Control System Experimentation itc

Under a Related Services Agree, nt

with the U.S. Department of [ I !

contract DE-ACOE-76RLO 1830:

Pacific Northwest Laborator:"

ichland, Washingtor $\$ 935 \%$

a) Human Affairs Resource Seattle, Washingtori 


\title{
Empirical Identification of User Information Requirements in Command and Control System Evaluation
}

\author{
Marvin C. Mcr.allum \\ Alvah C. Bittner, Jr. \\ Battelle Seattle Research Centers \\ Richard $V$. Badalamente \\ Pacific Northwest Laboratory
}

Bbiract

This paper summarizes a study that was conducted to address user information requirements for the Force Level Control System. It was the first in a series being conducted at the U.S. Army Tactical Command and Control system Experimentation Site (AES). User information requirements were jetermined via monitoring and classification of communications during a command and control exercise, as well as through subsequent exercise participant input. Separate measures of observed communication frequency, rated importance, and rated perishability were obtained for a set of information elerients that comprised a comprehensive taxonomy of tactical command and control communications content. Analyses were then conducted to explore the relationships between frequency, importance, and perishability as well as develop a comprehensive index of criticality. The resulting comprehensive index of criticality is intended to be used by systems cevelopers in selecting the information to be conveyed and processed by the arce l.evel Control System. 


\section{Introduction}

The U.S. Army is currently developing the automated Force Level Control System (FLCS). The FLCS is a software systern being developed to assist in the collection and integration of tactical information. The ultimate function of the Fl.CS is to facilitate the commander's job of commanding and controlling his forces by providing a comprehensive summary of the battefield situation. Thus, a central concern during the development of this system is the identification of user information requirements. The present paper reports the first in a series of empirical evaluations, of Fl.CS user information requirements. The U.S. Army Tactical Command and Control System Experimentation Site (AES) has published a more thorough technical report of this research (MCCalluin, Bittner, \& Badalamente, October, 1989).

Method

Information requirements were identified by integrating findings from two converging data collection efforts. The first data collection effort involves remote monitoring the command and control communications of four principals and their immediate assistants in a brigade tactical operations center during a 72 hour exercise. Monitoring was accomplished through video cameras and microphones placed in the brigade tactical operations center and the interception of all brigade radio and telephone communications. Dependent measures recorcied by subject matter experts (SMES) for each monitored communication included: (i) classification of the commumication as an information request or transmittal, ( $i i)$ identification of the communication originator and recipient, ( $i i j)$ the tactical operation during which the communication occurred and ( $i v$ ) the content of the communication. Communication content was determined via reference to a comprehensive taxonomy of command and control communications.

The second data collection effort involved the collection of subjective ratings from the four brigade principals and their immediate assistants. Brigade personnel completed standardized forms to provide ratio-based importance and perishability ratings for a subset of the information elements comprising the taxonomy. For the purposes of ratings, importance was defined as "the relative importance of the information for battlefield decision making." Perishability was defined as "the length of time before a specific information element may be expected to be significantly changed with respect to an operation (e.g., its "half-life" during a Defense). Ratings were obtained for each of three operations comprising the exercise (defense, attack, and river crossing).

\section{Results}

A total of 2,536 voice communications involving one or more of the brigade principals were observed and classified by SMEs during the operation. Repeated Measures Analysis of Variance were conducted, using frequency logarithms, to determine the effects of three factors on information element: irequency: information element, operation (defense, attack, and river 
crossing), and information request versus transmittal. Information element frequencies were found to vary substantially $(E(61,122)=34.84, p<.00005)$. Additionally, the frequency of information element communication was found to interactively vary wit! tactical operations $(E(122,122)=2.45, \quad \mathrm{p}<.005)$.

Among the 66 information elements in the taxonomy, observed frequencies ranged from a high of 513 for communications dealing with Enemy Unit Locations to a low of 0 for communications dealing with six other information elements. The frequency distribution across information elements car be generally characterized as approximately declining with the reciprocal of element rank. Figure 1 depicts the frequency distribution for the 13 most-frequently communicated information elements which cumulatively account for over 80 percent of all communications.

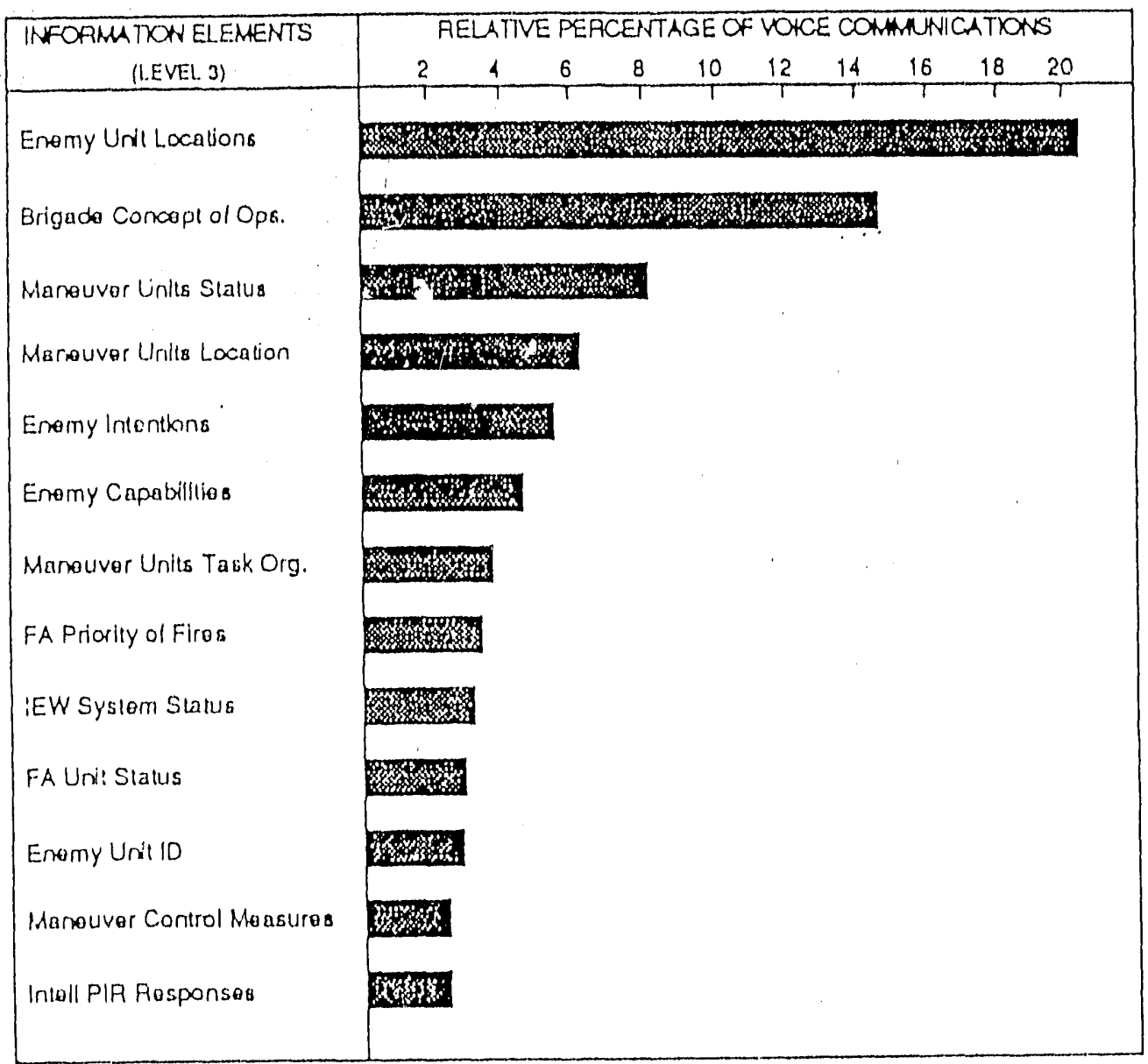

Figure 1. Relative Percentage of Information Elements Accounting for 80\% of All Voice Communications 
Importance ratings were based on a scale from 0 to 100. Average importance ratings ranged from a high of 100 for Division Mission to a low of 35.9 for Electronic Warfare Schedule. Perishability ratings were provided in hours. Average perishability ratings ranged from a low of 3 hours for both Target Location and Location of Enemy Barriers and Obstacles to a high of 35 hours for General Weather Conditions.

Importance and perishability ratings were logarithmically transformed prior to analysis. This class of transformations has been traditionally applied to direct-estimation data, such as the present ratings (Stevens, 1975). Repeated Measures Analys is of Variance analyses indicated that importance ratings varied across information elements $(E(20,40)=181.53$, $\mathrm{p}<.001)$ and the rated importance of information elements also varied across operations $(E(40,40)=9.12, p<.001)$. Analyses also revealed significant variation of perishability ratings across information elements $(E(37,74)$ $=10.03, p<.0001$ ) and the rated perishability of information element

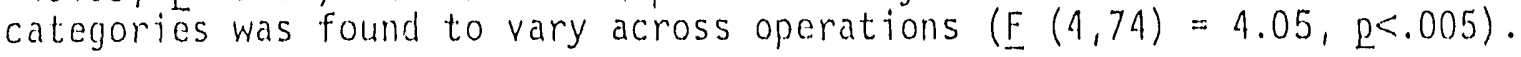

Both rated importance and rated perishability of information elements were found to be significantly correlated with observed frequency. For rated importance, $r(119)=.58, \mathrm{p}<.001$; and for rated perishability, $r(119)=-$ $.12, p<.00 \overline{1}$. It should be noted that the positive correlations between inforilation element rated importance and observed frequency, and the negative correlations between frequency and perishability were anticipated from control theory considerations.

Non-linear regression was used to predict the observed frequency of comminications using the averaged importance and perishability ratings for each tactical operation. The resulting fitted relationships were of the general form presented in Equation 1.

$$
\operatorname{In}\left(\overline{\text { Freq }+1)}=C_{0}+2.89 * \operatorname{Ln}(\text { Import }+1)-.679 * \operatorname{Ln}(\text { Perish }+1) \quad(E Q .1)\right.
$$

Referring to Equation 1, In indicates a natural logarithmic transformation; Freq is information element observed frequency, Import and Perish are the liean ratings, and $C_{0}$ was a fitted constant which varied with operations. Multivariate correlation analysis supported the significance of this combination of the rating variables. Predicted frequency, using the combination of rating variables shown in Equation 1 was found to be significantly correlated with observed frequency $(\underline{R}(5,117)=0.68, p<$ $.0001)$.

A procedure for computing a comprehensive index of information element criticality was developed, based upon the analyses described above and a consideration of the nature of the separate measures used in this study. The basic premise in developing this comprehensive index was that the "expected" frequency of observed communications with in the TOC provided the primary measure of criticality. Importance and perishability ratings, in light of this, were judged to provide an additional contribution to the specification of a comprehensive criticality index in three related ways. First, ratings of 
importance and perishability provide a broader basis upon which to base an index of criticality. Second, the ratings are based on brigade principals' more general consideration of tactical circumstances, resulting in increased generality of the findings. Finally, for infrequentiy communicated information elements, importance and perishability ratings provide a means of better differentiating between information elements. Based on these considerations, it was determined that observed communication frequency and the combination of rating scores for each information element would be weighted equally in computing a comprehensive index of criticality. Additionally, the separate weights for the rating measures would be based upon Equation 1. The resulting calculation of comprehens ive criticality across tactical operations is the geometric mean of observed and predicted information element frequency:

$$
\operatorname{Ln}(\text { Criticality })=\operatorname{Ln}(\text { Freq }+1)+\operatorname{Ln}(\text { Freq }+1) \quad(E Q .2)
$$

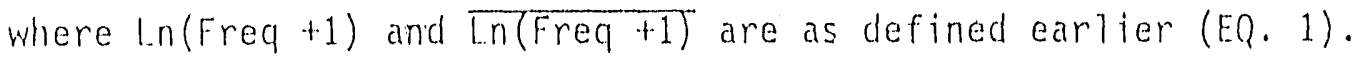

Discussion

The prescnt approach towards the determination of user information requirements has two major advantages over the more commonly employed approach of expert panel evaluation. First, it is based on operationalized measures which are amenable to replication. Second; the measures upon which it is based were obtained within the context of tactical operations, enhancing their validity.

The resulting criticality measures are intended to be used by systell designers responsible for determining the content and format of information to be conveyed and processed by the Fl.CS. By combining the separate measures into a single index of information element criticality, the current method is intended to provide a means of conducting tradeoff analys is of alternative system inforillation loads.

The general approach of calculating a composite information element criticality inciex has recentily been replicated in a second study of brigade command and control information requirements. In that study, comparable correlations between information eleme frequency and rated importance and perishability were obtained. Additiona!ly, the composite calculation (E). :) had comparable weights. However, the criticality of specific information elements varied from that reported here. This latter finding, in conjunction with the obtained interactions of information element frequency across tactical operations, points to the need to obtain a representative sample of data prior to final specification of infermation requirements.

Further examination of the individual information elements also points to a fundamental difference in the type of information element flowing within the command and control system. On the one hand, there is a class of information elements that constitutes inputs to the commander's decision process. These 
are represented by elements such as enemy unit location and st itus, maneuver unit status, and anmunition status. On the other hand, there is a class of information elements that constitutes outputs of the decision process.

Examples of outputs are brigade mission and brigade concept of operations.

Dur observation of commander and staff functioning during the exercise led us to conclude that the commander's decision making process is a cyclical process, which is reiterated as new information becomes available and uncertainties are resolved. Thus, outputs of the decision process are fed back through the process and plans are mafified and refined, as illustrated in Figure 2. Future research will examine the empirical relationship between criticality, perishability, and frequency of information elements as a function their role as decision process inputs versus outputs.

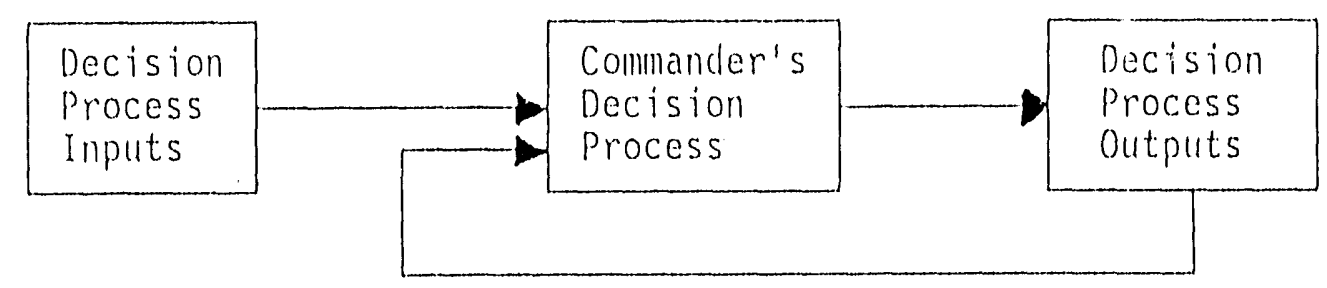

\section{References}

Stevens, S.S. 1975. Psychophysics. John Wiley \& Sons. New York, New York.

McCallum, M.M., Bittner, A.C., Jr, and Badalamente, R.V. October, 1989. Force Level Control System Exercise \#1: Brigade Tactical Operations Center Information Flow and Commander's Critical Information Requirements. U.S. Army Development and Employment Agency. Fort Lewis, Washington. 

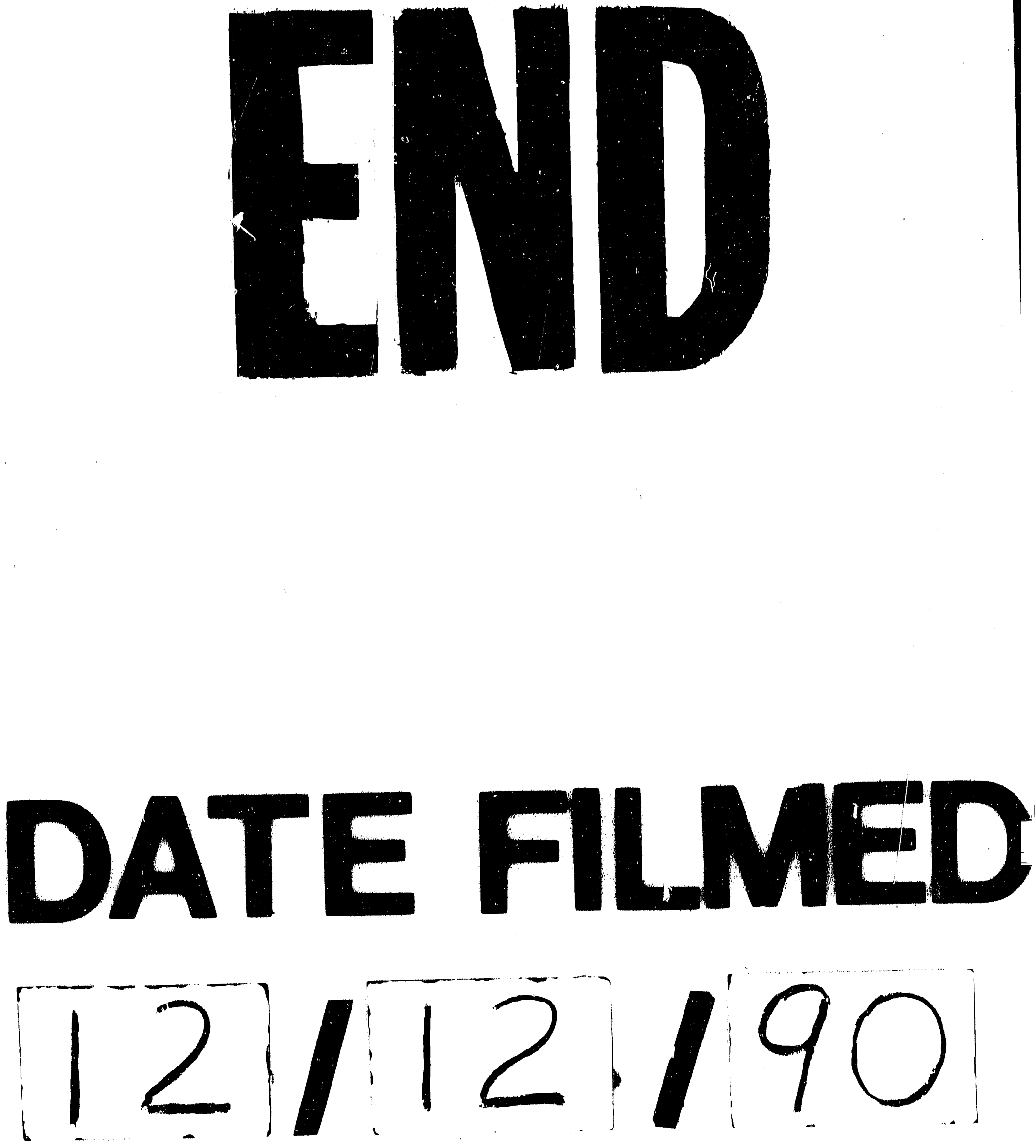
